\title{
La Unión Europea: limitación de la soberanía, al menos, dos beneficios colaterales
}

\author{
The European Union: limiting sovereignty, at least two collateral benefits
}

\author{
JOSÉ IGNACIO MORILLO-VELARDE PÉREZ* \\ Catedrático de Derecho Administrativo \\ Universidad Pablo de Olavide (España) \\ jimorper@upo.es \\ https://orcid.org/0000-0002-9363-1623
}

\begin{abstract}
Resumen: Se destaca que el ordenamiento jurídico de la Unión Europea por sus características y principios de relación con los ordenamientos de los Estados miembro ha ayudado poderosamente a encauzar, si no resolver por completo dos cuestiones pendientes en el derecho público español: la responsabilidad patrimonial del poder legislativo y la huida del derecho administrativo.
\end{abstract}

Abstract: It is highlighted that the legal system of the European Union, due to its characteristics and principles of relationship with the laws of the member states, has powerfully helped to chan-nel, if not completely resolve, two pending issues in Spanish public law: the patrimonial res-ponsibility of the legislative power and the run away of administrative law.

Palabras claves: responsabilidad patrimonial, legislador, contratos públicos, huida del derecho administrativo.

Keywords: patrimonial responsibility, legislator, public contracts, the run away of administrative law.

Sumario: 1. INTRODUCCIÓN. 2. LA RESPONSABILIDAD PATRIMONIAL DEL ESTADO LEGISLADOR. 3. LA INCIDENCIA DEL DERECHO DE LA UNIÓN EUROPEA EN EL PROBLEMA DE LA HUIDA DEL DERECHO ADMINISTRATIVO. 3.1. Una situación detectada hace tiempo sin soluciones a la vista. 3.2. La posible solución de la mano del derecho de la Unión Europea. 4. CONCLUSIÓN. 5. BIBLIOGRAFÍA.

* Ha sido Profesor Titular de Derecho Administrativo de la Universidad de Cádiz en los períodos 1980-81, 19831987 y 1990-92, y Catedrático de Derecho Administrativo de la Universidad de Cádiz durante los años 1994-2002. Ha sido Director del Departamento de Derecho Público de la Universidad de Cádiz (2002) y dos veces Decano de la Facultad de Derecho de la Universidad de Cádiz en los años 1986-1987 y 1995-98. 


\section{INTRODUCCIÓN}

Ha sido frecuente en estos últimos años cifrar balances negativos sobre la pertenencia de España -y lo mismo otros estados- a la Unión Europea en el argumento de la merma de soberanía que comporta. Posiblemente la renuncia a la política monetaria por parte de los estados incorporados a la zona euro, entre ellos el Reino de España, sea el elemento más visible que expresa esta circunstancia. La discutible actitud de algún estado miembro ante euroórdenes emanadas de tribunales españoles en estos últimos tiempos, aunque el fenómeno no es nuevo, ha contribuido a alimentar estas posiciones, sin duda. Naturalmente, la consideración aislada de estas y otras deficiencias en el funcionamiento de la Unión Europea puede justificar los más variados juicios al respecto. Aunque no soy experto en las concretas materias aludidas, por más que como ciudadano tengo mi opinión al respecto, que dista bastante del argumentario de los descontentos, por lo que no comparto la actitud de los que genéricamente y presos de una, diría que comprensible nostalgia, denostan de una entidad que viene a detentar una soberanía propia compartiéndola así la con los estados nacionales ${ }^{1}$.

Admitido el hecho de la merma de soberanía no por ello hay que lamentar una pérdida. Tan cierto como ello es que fuera un acto de ejercicio de soberanía lo que vinculó a España con la Unión en 1986, entonces aún la Comunidad Económica Europea. No creo, pues, que es más libre aquel que menos se compromete, sino el que valora sus compromisos y hace honor a ellos, mientras subsistan ${ }^{2}$. Aunque no hubiera referéndum es una obviedad que la incorporación fue querida mayoritariamente por los españoles, se hizo de manera impecable conforme con la legalidad y aún hay quienes, deseando separarse de España, pretenden continuar su pertenencia en la Unión ${ }^{3}$.

Esta situación se manifiesta, entre otras concreciones, en la superposición a nuestro derecho tradicional de un nuevo orden normativo, el derecho comunitario o, ahora mejor, derecho de la Unión, a través de su supremacía y de su efecto directo, que de esta forma, completa, otorgándole un perfil original, al mismo derecho español, aún a pesar de las dificultades de integración que se han puesto de manifiesto ${ }^{4}$.En términos, quizá hoy en desuso, podríamos hablar de un crecimiento de la clásica pirámide kelsenniana precisamente por su cúspide.

\footnotetext{
${ }^{1}$ SARMIENTO, D., El Derecho de la Unión Europea, 2ª ed., Marcial Pons, 2018, pág. 43.

${ }^{2}$ En cualquier caso, no conviene exagerar ni dejarse llevar por tópicos y eslóganes. Como muy bien se ha expuesto, las competencias que ejerce la Unión procedentes de los Estados son cedidas, no transferidas, por lo que en cualquier momento se puede producir una reversión en la situación (SARMIENTO, D., El Derecho de la Unión Europea, op. cit., pág. 106 y 365 y ss.) Por otra parte, es lo que estamos viendo con el caso del Reino Unido, a cuyo respecto son muy interesantes las reflexiones de MANGAS MARTÍN, A., "Cuestiones Jurídicas en torno al Brexit: notificación, plazos, formación de la voluntad, orientaciones y revocación”, en Anuario Español de Derecho Internacional, nº 34, 2018, pág. 817.
}

${ }^{3}$ Por lo que respecta a nuestro tema $c f r$. NIETO, A., "El Derecho comunitario europeo como Derecho común vulgar”, en Revista de Administración Pública, n 200, mayo- agosto, 2016, en especial pág. 36.

${ }^{4}$ NIETO, A., “El Derecho comunitario europeo como Derecho común vulgar”, op. cit. págs. 34-35. 
A estas alturas todas estas afirmaciones podrían calificarse de obviedades, pero me parecía importante recordarlas en el comienzo de estas reflexiones, cuyo alcance se limita a poner de relieve la incidencia del derecho de la Unión en dos cuestiones o asuntos que se han venido arrastrando en nuestro derecho desde hace ya bastantes años: la culminación del proceso de sometimiento a responsabilidad patrimonial de los poderes públicos, asunto, si se quiere más ligado al derecho constitucional y en la clásica cuestión de la huida del derecho administrativo, centrada naturalmente en esta rama del ordenamiento jurídico.

Desde la perspectiva apuntada la evidente merma de soberanía que el efecto directo y la supremacía del ordenamiento de la Unión sobre los estatales comporta, no puede considerase una mala noticia antes, al contrario, traza los presupuestos indispensables para que en relación con las temáticas aludidas pueda avistarse una solución satisfactoria. Es sabido, pues, que soberanía y derecho son dos realidades de muy difícil coexistencia y éste sólo es posible en tanto que se limita a aquélla. La cuestión no es, pues, limitación o no, sino qué limitación ${ }^{5}$.A este respecto, no está de más recordar que la gran revolución que alumbró el estado de derecho se cifró precisamente en la privación de la soberanía al poder real centrándola en el legislativo, al par que se sometía al ejecutivo a la ley, expresión de la voluntad popular encarnada en aquél en un delicado juego de frenos y contrapesos que no es preciso recordar.

Es precisamente ésta la perspectiva pertinente para considerar en este momento el derecho de la Unión: un nivel normativo desde el que someter a exigencias jurídicas posibles veleidades de los poderes legislativos estatales inspiradas en muchas ocasiones más en la lógica del atajo político que de las exigencias de un orden jurídico fundamentado en la dignidad de la persona y el respeto a sus derechos. Con estas reflexiones no deseo sacralizar el derecho de la Unión y las soluciones concretas que aporta, pero aun reconociendo errores y deficiencias, no puede desconocerse su condición de garantía de los pilares fundamentales del estado de derecho.

\section{LA RESPONSABILIDAD PATRIMONIAL DEL ESTADO LEGISLADOR}

No puedo ocultar que la lectura del art. 139.3 de la Ley 30/1992, de 26 de noviembre, de Régimen Jurídico de las Administraciones públicas y de Procedimiento Administrativo Común me ha parecido siempre lo más parecido a un brindis al sol:

Las Administraciones Públicas indemnizarán a los particulares por la aplicación de actos legislativos de naturaleza no expropiatoria de derechos y que éstos no tengan el deber jurídico de soportar, cuando así se establezcan en los propios actos legislativos y en los términos que especifiquen dichos actos.

Conviene subrayar que este apartado, mantenido como el primer párrafo del art. 32. 3 de la de la Ley 40/2015, de 1 de octubre, de Régimen Jurídico del Sector Público (LRJSP) representa la situación original de la regulación de esta materia en nuestro derecho. Aparentemente, al

\footnotetext{
${ }^{5}$ En mi opinión la aludida limitación de la soberanía del Estado se justifica sobradamente en atención a los valores de la Unión (SARMIENTO, D., El Derecho de la Unión Europea, op. cit., pág. 46 y ss.).
} 
menos, nada más inútil ${ }^{6}$, pues por lo que respecta a los actos legislativos de naturaleza expropiatoria, a los que se alude para excluirlos de su ámbito de aplicación, su indemnizabilidad viene impuesta por el propio concepto de expropiación, que consagra la Constitución (art. 33. 2), en consecuencia, la ley no aporta novedad alguna en lo que a ellos se refiere. Respecto de los actos legislativos de naturaleza no expropiatoria se deja muy claro que la administración indemnizará cuando el legislador quiera y como quiera. Es lo que se viene a decir ${ }^{7}$. No obstante, nada impide reconocer, como la autora citada en nota, que la previsión, limitada de un derecho a indemnización por daños causados por la aplicación de leyes en la Ley 30/1992, ha servido para despejar algunas dudas en cuanto a la «posibilidad» de admitir un sistema de responsabilidad por actos legislativos, pero no para aclarar el alcance de esta responsabilidad. De estas dudas es exponente un contexto jurisprudencial vacilante ${ }^{8}$ y no exento de contradicciones hasta diversas sentencias del Tribunal Supremo de 29 de febrero de $2000^{9}$, proceso que culmina precisamente casi diez años después de que el Tribunal de Justicia de la Comunidad Europea con su sentencia de 19 de noviembre de 1991, la famosa sentencia Francovich, reconociera la responsabilidad de los Estados por daños ocasionados por el incumplimiento del Derecho comunitario como un principio inherente al Tratado. No creo, por tanto, que se pueda dudar de la existencia de alguna conexión y un cierto arrastre de la jurisprudencia española por la del Tribunal de Justicia de la Unión ${ }^{10}$. El fruto desde la perspectiva legal, de momento, es el reconocimiento de la responsabilidad por daños que se contiene en el artículo 32.3 LRJSP:

La responsabilidad del Estado legislador podrá surgir también en los siguientes supuestos, siempre que concurran los requisitos previstos en los apartados anteriores:

a) Cuando los daños deriven de la aplicación de una norma con rango de ley declarada inconstitucional, siempre que concurran los requisitos del apartado $4^{11}$.

${ }^{6}$ Sin embargo, parece que algunos autores ven aquí el reconocimiento de responsabilidad por daños causados por leyes constitucionales.

${ }^{7}$ AHUMADA RUIZ, M.A., "Responsabilidad patrimonial del Estado por las leyes inconstitucionales (o el derecho a no ser perjudicado por una ley inconstitucional)", en Revista Española de Derecho Constitucional, núm. 42, 2001, pág. 307. También muy crítico al respecto, GALÁN VIOQUE, R., "A vueltas con la regulación de la responsabilidad del Estado legislador (Un nuevo intento introducido en el Proyecto de Ley de Régimen jurídico del sector público de limitar el alcance de la responsabilidad del Estado Legislador, esta vez en su vertiente del ilícito legislativo)", Documentación Administrativa, nueva época, $\mathrm{n}^{\circ}$ 2, 2015.

${ }^{8}$ Son de destacar en este punto las reticencias de un importante sector de la doctrina administrativista frente a la jurisdicción de los tribunales contencioso-administrativos para decidir acciones de condena contra el legislador (GARCÍA DE ENTERRÍA, E., La responsabilidad patrimonial del Estado legislador en el Derecho español, Civitas, 2005, pág. 115 y ss.).

${ }^{9}$ La propia sentencia resalta esta vinculación: "Responde sin duda esta normación a la consideración de la responsabilidad del Estado legislador como un supuesto excepcional vinculado al respeto a la soberanía inherente al poder legislativo".

10 "Existe, en efecto, una notable tendencia en la doctrina y en el derecho comparado a admitir que, declarada inconstitucional una ley, puede generar un pronunciamiento de reconocimiento de responsabilidad patrimonial cuando aquélla ocasione privación o lesión de bienes, derechos o intereses jurídicos protegibles" (STS 29 de febrero de 2000).

${ }^{11}$ Art. 32. 4 LRJSP: "Si la lesión es consecuencia de la aplicación de una norma con rango de ley declarada 
b) Cuando los daños deriven de la aplicación de una norma contraria al Derecho de la Unión Europea, de acuerdo con lo dispuesto en el apartado $5^{12}$.

No es mi intención acometer un análisis crítico de este precepto. Hay muchas aportaciones doctrinales muy estimables, algunas de las cuales cito a lo largo de estas páginas, también una extensa jurisprudencia, que, sin perjuicio de momentos de vacilación y oscuridad, constituye un valioso antecedente para enjuiciar el texto legal. Solamente quisiera hacer algunas reflexiones que se sitúan en la periferia de esta temática pero que nos pueden permitir calibrar de forma ponderada y realista la influencia en este aspecto del derecho de la Unión Europea:

A) En primer lugar, creo conveniente subrayar el hecho histórico del papel que ha desempeñado la Unión Europea en el reconocimiento de la responsabilidad patrimonial del Estado legislador. En el supuesto de la responsabilidad por daños derivados de incumplimiento de norma del derecho de la Unión la influencia de éste es una obviedad. En el otro, responsabilidad derivada de daños ocasionados por ley declarada inconstitucional, la relación es indirecta pues, efectivamente, a su reconocimiento llegó de la mano de la jurisprudencia española, pero no cabe duda que el derecho de la Unión propició el entorno adecuado para su aceptación ${ }^{13}$. Esta circunstancia es especialmente relevante si consideramos el vacío constitucional que nos afecta en este aspecto, al no existir en la Constitución Española de 1978 referido a la responsabilidad patrimonial del legislador, un precepto equivalente al art. 106. 2 por lo que atañe a la indemnizabilidad de daños procedentes del funcionamiento de los servicios públicos ni al art.121 respecto de los causados por el funcionamiento anormal de la Administración de Justicia. Como es sabido, la responsabilidad del legislador no tiene ninguna expresión de reconocimiento específico, al margen del genérico sometimiento de los poderes públicos a responsabilidad consagrado en su art. 9.3, por tanto, sin mención alguna a consecuencias de carácter patrimonial ${ }^{14}$.

inconstitucional, procederá su indemnización cuando el particular haya obtenido, en cualquier instancia, sentencia firme desestimatoria de un recurso contra la actuación administrativa que ocasionó el daño, siempre que se hubiera alegado la inconstitucionalidad posteriormente declarada”.

12 Art. 32.5 LRJSP: "Si la lesión es consecuencia de la aplicación de una norma declarada contraria al Derecho de la Unión Europea, procederá su indemnización cuando el particular haya obtenido, en cualquier instancia, sentencia firme desestimatoria de un recurso contra la actuación administrativa que ocasionó el daño, siempre que se hubiera alegado la infracción del Derecho de la Unión Europea posteriormente declarada. Asimismo, deberán cumplirse todos los requisitos siguientes:

a) La norma ha de tener por objeto conferir derechos a los particulares.

b) El incumplimiento ha de estar suficientemente caracterizado.

c) Ha de existir una relación de causalidad directa entre el incumplimiento de la obligación impuesta a la Administración responsable por el Derecho de la Unión Europea y el daño sufrido por los particulares”.

${ }^{13}$ En los antecedentes de la sentencia que vengo citando, ésta se hace eco de la evolución del principio de responsabilidad en el Derecho de la Unión.

${ }^{14}$ MORENO MOLINA, J. A., "Las novedades en la regulación por las leyes 39 y 40/2015 de la responsabilidad patrimonial y la potestad sancionadora de las administraciones públicas", en Revista Española de Derecho Administrativo, núm. 179, 2016. 
B) Junto a la satisfacción que suscita la constatación antes expresada surge el impacto de las indudables carencias:

a) Es obvio que la Ley de Expropiación Forzosa de 1954 y normas posteriores que la fueron desarrollando y complementando hasta culminar en el art. 106. 2 CE marcaron unas pautas difícilmente superables en cuanto a nivel de protección contra daños procedentes de la acción, en el sentido más amplio de esta expresión, del poder ejecutivo ${ }^{15}$. En lenguaje coloquial podríamos decir que se puso el listón muy alto. Es por esto que, desde mi punto de vista, resulta difícil justificar las limitaciones procesales (agotamiento de vías de recurso en determinadas circunstancias) y de fondo (vulneración suficientemente caracterizada de norma comunitaria) que finalmente ha acogido nuestro legislador, como desde muy respetables instancias se vienen aduciendo con la finalidad de filtrar los supuestos indemnizables.

No quiero decir con ello que deba necesariamente indemnizarse cualquier daño antijurídico sino que, en mi opinión, las circunstancias condicionantes de la indemnizabilidad sólo pueden configurarse desde la perspectiva del propio daño - no prescrito- y de lo exigible en cada momento al autor del mismo, en nuestro caso las administraciones públicas o el poder legislativo ${ }^{16}$. Atender a otros condicionamientos, como los de carácter financiero, sólo puede admitirse como una declaración de impotencia y aceptarlos como una quiebra del sistema que se puede justificar de la forma que se desee.

En este sentido me parece criticable la exigencia de que para que proceda la indemnización por daños derivados de actos administrativos dictados al amparo de ley posteriormente declarada inconstitucional o de norma declarada contraria al derecho de la Unión, el particular haya obtenido, en cualquier instancia, sentencia firme desestimatoria de un recurso contra la actuación administrativa que ocasionó el daño, siempre que se hubiera alegado la inconstitucionalidad posteriormente declarada. Esta exigencia impuesta por la LRJSP tiene su antecedente inmediato en la STJUE de 26 de febrero de 2010 cuyo apartado 48 no puede ser más contundente ${ }^{17}$. Se rectifica así la jurisprudencia española que no venía exigiendo este

\footnotetext{
15 No desconozco las actitudes revisionistas producidas en los últimos años del siglo pasado desde distintos sectores, ni creo que la regulación española de esta materia sea perfecta, pero es indudable que se creó un sistema con unos rasgos muy definidos que fácilmente puede constituir un paradigma (COBREROS MENDAZONA, E., Responsabilidad patrimonial del Estado por incumplimiento del Derecho de la Unión Europea, Iustel, 2015, pág. 235).

${ }^{16}$ En este sentido COBREROS ha recordado "la paulatina admisión jurisprudencial de un cierto margen de tolerancia, sobre todo en el ejercicio de potestades discrecionales. Y sin perjuicio, asimismo, de algunas peculiaridades o especificidades que iban detectándose en determinados ámbitos, como puede ser, por ejemplo, el de la responsabilidad sanitaria, donde se puede apreciar, por un lado, cierto rigor al exigir un comportamiento no amparado por la lex artis ni por el nivel de los conocimientos o de la técnica, y, por otro lado, la introducción de un novedoso (entre nosotros) concepto indemnizatorio, como es el de la pérdida de oportunidad (sanitaria, en el caso)" (COBREROS MENDAZONA, E., "La pertenencia a la Unión Europea y su repercusión en la responsabilidad patrimonial”, en Revista de Administración Pública, nº 200, pág. 317).

17 “El Derecho de la Unión se opone a la aplicación de una regla de un Estado miembro en virtud de la cual una reclamación de responsabilidad patrimonial del Estado basada en una infracción de dicho Derecho por una ley nacional declarada mediante sentencia del Tribunal de Justicia dictada con arreglo al artículo 226 CE sólo puede estimarse si el demandante ha agotado previamente todas las vías de recurso internas dirigidas a impugnar la validez del acto administrativo lesivo dictado sobre la base de dicha ley, mientras que tal regla no es de aplicación
} 
requisito para reconocer el derecho a indemnización en los casos de daños derivados de actos administrativos cubiertos por una ley declarada posteriormente inconstitucional y si cuando se trataba de daños producidos por actos contrarios al derecho de la Unión.

Una lectura apresurada de estos hechos lleva, sin duda, a considerar en este punto al derecho de la Unión como obstaculizador del derecho a la indemnización y por tanto a cerrar las puertas a la misma, pero esta conclusión es, sin duda, precipitada $^{18}$, pues ha sido el legislador español quien ha impuesto el mencionado requisito tomando al derecho de la Unión como coartada. Como se ha dicho, la regulación vigente ha producido un giro radical, de carácter restrictivo en relación con la práctica jurisprudencial existente ${ }^{19}$. Ciertamente la mencionada STJUE rechaza la disparidad de requisitos procedimentales para reclamar indemnización por daños derivados de norma declarada inconstitucional y de incumplimiento del derecho de la Unión, respectivamente. El texto citado en nota no puede ser más claro ${ }^{20}$, pero de él no puede extraerse la consecuencia que deduce el legislador español de 2015.

En efecto, no parece razonable que si el Tribunal Supremo ${ }^{21}$ ha sostenido que no puede considerarse una carga exigible al particular recurrir un acto adecuado a una ley posteriormente declarada inconstitucional por la presunción de constitucionalidad de que goza la ley y porque los particulares no son titulares de la acción de inconstitucionalidad ${ }^{22}$, el legislador se desentienda y exija tal requisito, para no incurrir en la situación de discriminación que entraña exigirlo en los supuestos de incumplimiento del derecho de la Unión.

Al margen de si nos encontramos ante dos situaciones diferentes, lo que desestima el Tribunal de la Unión y apoya una importante doctrina ${ }^{23}$,es la situación de perjuicio de las reclamaciones

a una reclamación de responsabilidad patrimonial del Estado fundamentada en la infracción de la Constitución por la misma ley declarada por el órgano jurisdiccional competente”.

18 GALÁN VIOQUE, R., “A vueltas con la regulación de la responsabilidad del Estado legislador (Un nuevo intento introducido en el Proyecto de Ley de Régimen jurídico del sector público de limitar el alcance de la responsabilidad del Estado Legislador, esta vez en su vertiente del ilícito legislativo)", op. cit.

${ }^{19}$ COBREROS MENDAZONA, E., "El diálogo judicial para la construcción de la responsabilidad patrimonial del estado por leyes contrarias al derecho de la unión europea", Anuario de la Facultad de Derecho de la Universidad Autónoma de Madrid, nº 22, 2018, pág. 468.

${ }^{20}$ COBREROS MENDAZONA, E., "La pertenencia a la Unión Europea y su repercusión en la responsabilidad patrimonial", op. cit., pág. 331.

${ }^{21}$ STJUE, de 26 de enero de 2010, apartado 18, citando al propio Tribunal Supremo español: "En estas circunstancias, si el agotamiento previo de las vías de recurso administrativas y judiciales contra el acto administrativo lesivo se exigiera como requisito para poder interponer una reclamación de responsabilidad patrimonial basada en la infracción de la Constitución, se impondría a los justiciables la carga de impugnar el acto administrativo dictado en aplicación de la ley supuestamente inconstitucional utilizando, en primer lugar, la vía administrativa y, en segundo lugar, la vía contenciosa, agotando todas las instancias hasta que uno de los órganos jurisdiccionales que conocen del asunto decida finalmente formular la cuestión de inconstitucionalidad de dicha ley ante el Tribunal Constitucional. Tal situación sería desproporcionada y tendría consecuencias inaceptables".

${ }^{22}$ COBREROS MENDAZONA, E., "La pertenencia a la Unión Europea y su repercusión en la responsabilidad patrimonial", op. cit..

${ }^{23}$ CORTÉS MARTÍN, J.M., “Jurisprudencia del Tribunal de Justicia de la Unión Europea”, en Revista de Derecho comunitario Europeo, enero-abril, 2010, pág. 593; ALONSO GARCÍA, R. "La responsabilidad patrimonial del 
por incumplimiento del derecho de la Unión lo que se condena, por ello la ley española pudo y debió optar por la solución inversa, que no le hubiera sido reprochada por el derecho de la Unión, y no exigir el mencionado requisito procedimental en ninguno de los casos. Me cuesta trabajo pensar que con ello se hiciera peligrar la Hacienda Pública española. Por otra parte, el límite temporal previsto en el párrafo segundo del apartado 1 del art. 34 LRJSP $^{24}$ deja a salvo las exigencias más elementales de seguridad jurídica y, dada la premiosidad que suele aquejar a nuestro Tribunal Constitucional, dejará fuera de la indemnizabilidad una gran cantidad de casos. Al margen de lo discutible para algunos ${ }^{25}$ de esta última limitación la acumulación de ambas no deja de ser redundante ${ }^{26}$.

De ahí que cupiera justamente, la solución inversa a la finalmente adoptada por el legislador, esto es, no imponer el requisito en cuestión en ninguno de los supuestos del apartado 3 del art. 32 LRJSP citado más atrás. Esta era la solución por la que se inclinara el Tribunal Supremo ${ }^{27}$ que, como se ha dicho ${ }^{28}$, ha sido enmendado por el legislador animado, tal vez, por el apoyo de una importante mayoría de la doctrina administrativista.

Por lo que respecta a los requisitos de fondo es apreciable que la LRJSP no mantiene el mismo criterio de la unificación que debería llevar bien a suprimir los que exige el TJUE para la responsabilidad derivada de infracción del derecho de la Unión o matizar de la misma forma la regulación de la responsabilidad derivada de daños producidos por leyes declaradas inconstitucionales, que la ley no matiza de ninguna manera. En efecto, la lectura del art. 32.5 a) y b) revela dos requisitos de fondo que no se contemplan en su apartado 4. Hay, por tanto,

Estado-legislador, en especial en los casos de infracción del Derecho comunitario: a propósito del auto del Tribunal Supremo de 1 de febrero de 2008 y la cuestión prejudicial planteada al TJCE (C-118/08)", en Cuadernos de Derecho Local, nº 19, 2009, pág. 181 y ss.

${ }^{24}$ Solo se indemnizarán los daños producidos "en el plazo de los cinco años anteriores a la fecha de la publicación de la sentencia que declare la inconstitucionalidad de la norma con rango de ley o el carácter de norma contraria al Derecho de la Unión Europea".

${ }^{25}$ GALÁN VIOQUE, R., “A vueltas con la regulación de la responsabilidad del Estado legislador (Un nuevo intento introducido en el Proyecto de Ley de Régimen jurídico del sector público de limitar el alcance de la responsabilidad del Estado Legislador, esta vez en su vertiente del ilícito legislativo)", op. cit.

${ }^{26}$ GARCÍA DE ENTERRÍA, E., La responsabilidad patrimonial del Estado legislador en el Derecho español, op. cit., págs. 272 y ss.

${ }^{27}$ Entre otras, la STS 4975/2010, de 17 de septiembre de 2010: "Sentado lo anterior puede afirmarse que no constituye obstáculo para el ejercicio de la acción de responsabilidad patrimonial por parte de la COOPERATIVA DE ARMADORES DE PESCA DEL PUERTO DE VIGO, SOCIEDAD COOPERATIVA LIMITADA, el hecho de que se aquietara con las regularizaciones tributarias practicadas por la Inspección de Tributos en las liquidaciones tributarias relativas al IVA en las que se habia aplicado la regla de prorrata posteriormente declarada contraria al Derecho comunitario por la STJCE de 6 de octubre de 2005"; GUICHOT REINA, E., "La responsabilidad del Estado legislador por infracción del Derecho de la Unión Europea en la jurisprudencia y en la legislación española la luz de los principios de equivalencia y efectividad", en Revista Española de Derecho Europeo, no 60, 2016; COBREROS MENDAZONA, E., "El diálogo judicial para la construcción de la responsabilidad patrimonial del estado por leyes contrarias al derecho de la unión europea”, op. cit., pág. 439.

${ }^{28}$ GUICHOT REINA, E., "La responsabilidad del Estado legislador por infracción del Derecho de la Unión Europea en la jurisprudencia y en la legislación españolas a la luz de los principios de equivalencia y efectividad", op. cit.. 
una clara disparidad en la regulación de uno y otro supuesto ${ }^{29}$. Pero creo que no puede criticarse al legislador en este punto y en cualquier caso no me parece aceptable una crítica que conduzca a una unificación de regímenes de carácter restrictivo a la manera como ha sucedido con los requisitos procesales como sostiene una doctrina muy estimable por otra parte ${ }^{30}$. Las razones que se esgrimen para justificar una regulación restrictiva son muy valorables, sin duda, pero, en mi opinión, si no se manejan con extrema cautela pueden concluir en la frustración de la funcionalidad de la institución misma ${ }^{31}$.

A la hora de formular un juicio sobre esta cuestión conviene no olvidar cual es el fundamento o causa justificativa de estas indemnizaciones. No es esta la sede adecuada para extenderse en este aspecto. Es cierto que se han formulado distintos fundamentos de la responsabilidad patrimonial de las administraciones públicas que bien podrían trasladarse a los supuestos que contemplamos. No tengo duda de que si la responsabilidad de los entes públicos se justifica como un mecanismo de control o como una especie de seguro general, como se ha dicho, las regulaciones restrictivas pueden tener alguna razonable justificación, pero si de lo que se trata es de salvaguardar el principio de igualdad ante las cargas públicas, como a mí me parece, no son posibles las restricciones o limitaciones basadas en razones de conveniencia por más atinadas que sean, habrá que indagar un remedio para tales circunstancias, si en un momento dado la indemnización fuera imposible.

Hace ya años se arguyó contra el régimen de la responsabilidad objetiva de las Administraciones públicas el posible detrimento de la Hacienda pública. Algunos vaticinaban una especie de cataclismo provocado por la cantidad de indemnizaciones que las administraciones públicas tendrían que satisfacer. No ha sido así. Y me atrevo a asegurar que no será así. No podemos pensar, y menos en el caso del legislador, que la situación normal va a ser la de actos inconstitucionales o contrarios al Derecho de la Unión y que además causen daños efectivos y evaluables económicamente. Esto siempre ha ocurrido y ocurrirá, pero en circunstancias normales serán situaciones aisladas y perfectamente asumibles, como hasta ahora. En cualquier caso, no parece que sean asimilables a las posibilidades de causar daños por el funcionamiento de los servicios públicos (art. 106. $2 \mathrm{CE}$ ), las que puedan derivar dela acción de otros poderes constitucionales.

\footnotetext{
${ }^{29}$ COBREROS MENDAZONA, E., "El diálogo judicial para la construcción de la responsabilidad patrimonial del estado por leyes contrarias al derecho de la unión europea”, op. cit., pág.472.

${ }^{30}$ Por todos, COBREROS MENDAZONA, E., "El diálogo judicial para la construcción de la responsabilidad patrimonial del estado por leyes contrarias al derecho de la unión europea”, op. cit., pág.474.

31 "Pretende, cualquiera que sea la naturaleza del acto ilícito de que se trate, evitar que el riesgo de tener que cargar con las indemnizaciones de los daños alegados por las personas interesadas menoscabe la capacidad de la institución de que se trate de ejercer plenamente sus competencias en vista del interés general, tanto en el marco de su actividad normativa o que implique decisiones de política económica como en la esfera de su competencia administrativa, sin que recaigan sobre terceros, no obstante, las consecuencias de incumplimientos flagrantes e inexcusables"(COBREROS MENDAZONA, E., "La exigibilidad del requisito de la violación suficientemente caracterizada al aplicar en nuestro ordenamiento el principio de la responsabilidad patrimonial de los estados por el incumplimiento del derecho de la unión europea", en Revista de Administración Pública, n 196, 2015, pág. 19).
} 
b) Me parece también razonable resaltar lo que percibo como un curioso titubeo a la hora de imputar la responsabilidad: ¿es el responsable el Estado legislador? ¿lo son las administraciones públicas por actos amparados en normas de su respectivo legislador? Así mientras en el primer párrafo del apartado 3 del art. 32 se reconoce la responsabilidad de las administraciones públicas por actos legislativos de naturaleza no expropiatoria - planteamiento arrastrado desde 1992- los requisitos novedosos se configuran directamente como supuestos de responsabilidad del legislador. Sin embargo, en todos estos casos está siempre presente la intermediación de un acto administrativo. Tal vez por eso es coherente que quien paga es la administración y quien resuelve es el Consejo de Ministros (art. 92 de la Ley 39/2015, de 1 de octubre, de procedimiento administrativo común de las administraciones públicas), así como que quien materialmente causa el daño es la administración pública, aunque sea a través de un acto de aplicación de la ley inconstitucional o vulnerando el ordenamiento de la Unión Europea.

La situación es ciertamente ambigua: de un lado la causa del daño es el acto administrativo. En un sistema de responsabilidad objetiva la administración autora debería asumir su responsabilidad, mas mientras la ley de cobertura no se declare inconstitucional tal daño no sería indemnizable por no ser antijurídico y el particular tendría el deber de soportarlo. Ahora bien, desaparecida la cobertura que la ley posteriormente declarada inconstitucional proporcionaba, el daño deviene antijurídico y, en consecuencia, indemnizable. Se produce, por tanto, una confluencia de responsabilidades que justifica, a mi juicio, la solución adoptada por el legislador, además de otras razones obvias de carácter práctico.

Por último, se echa en falta el supuesto de responsabilidad del legislador por daños derivados de la propia ley sin la interposición de la acción administrativa a pesar de que ha habido casos ${ }^{32}$. Me parece difícil de que, ni siquiera en estos casos se pueda prescindir de la interposición de la administración a la hora de indemnizar. No imagino indemnizaciones importantes con cargo al presupuesto de las Cámaras legislativas del nivel que sea.

Esta cuestión, cuya trascendencia práctica quizá sea mínima, encierra sin embargo una carga teórica importante y es que, a mi juicio, no cabe hablar de una responsabilidad patrimonial autónoma del poder legislativo, no hay responsabilidad del legislador la responsabilidad es de la organización política en su conjunto, el estado o la comunidad autónoma por acto legislativo. La que afirmado así podría considerarse una simpleza conecta con otro problema de fondo que, si hay no parece preocupar en demasía, hizo correr ríos de tinta en el pasado: ¿Es la personalidad del estado o de la administración? Evidentemente al margen de lo que diga el derecho positivo, pero esto excede el propósito de estas líneas.

\section{LA INCIDENCIA DEL DERECHO DE LA UNIÓN EUROPEA EN EL PROBLEMA DE LA HUIDA DEL DERECHO ADMINISTRATIVO}

\footnotetext{
${ }^{32}$ GALÁN VIOQUE, R. "A vueltas con la regulación de la responsabilidad del Estado legislador (Un nuevo intento introducido en el Proyecto de Ley de Régimen jurídico del sector público de limitar el alcance de la responsabilidad del Estado Legislador, esta vez en su vertiente del ilícito legislativo)”, op. cit..
} 


\subsection{Una situación detectada hace tiempo sin soluciones a la vista.}

No puedo olvidar que hace cincuenta años una de mis primeras lecturas de derecho administrativo, siendo aún estudiante de la licenciatura, fuera esa importante y brillante obra del profesor CLAVERO ARÉVALO, Personalidad jurídica, Derecho general y Derecho singular en las Administraciones autónomas. Recientemente ha sido recordada por algunos ${ }^{33}$. Todavía puedo decir que me impresionó por su clarividencia, rigor expositivo y sencillez en la expresión. Pero para ser justo, también debo confesar que me desconcertó. Para una mente libre, entonces, de todo tipo de prejuicios de carácter técnico y dogmático, resultaba difícil entender lo que me parecía algo así como una especie de esquizofrenia del derecho, una huida del derecho administrativo propiciada por el propio derecho administrativo: una incoherente situación de división. El derecho administrativo surgido para dar respuesta a las necesidades y exigencias de la vida jurídica de la administración, terminaba abdicando de su fuerza normativa y llamando al derecho privado en su auxilio para la consecución de sus propias finalidades. Las invocaciones de la flexibilidad y agilidad de las normas del derecho estatutario frente al derecho general y, sobre todo, el desembarco final en el derecho privado, que en aquella obra se describen, no me parecieron otra cosa que la confesión más rotunda del fracaso del propio derecho administrativo. Entonces no entendía la tensión entre la acción del legislador y las recomendaciones y críticas de la doctrina ${ }^{34}$. Pero lo que siempre he tenido claro es que para un sector del ordenamiento jurídico regido por el principio de legalidad la corrección de esta deficiencia era una batalla perdida sin la colaboración del legislador. Ésta naturalmente ha estado muy lejos de producirse ${ }^{35}$ a pesar de los más encomiables esfuerzos en que se empeñaran diversos autores ofreciendo fórmulas y criterios como solución. Ha tenido que ser el derecho gris de la burocracia de Bruselas $^{36}$ el que de una forma bastante eficaz ha permitido un encauzamiento del problema, pues no me atrevo a afirmar su total erradicación. Sin perjuicio de su falibilidad y contingencia, hoy por hoy, podemos hablar de una considerable contracción del mismo.

De momento la supremacía del derecho de la Unión Europea en un considerable recorte de las posibilidades soberanas del legislador español, viene a ayudarnos a encarar una situación que desde la perspectiva interna es sencillamente irresoluble, al menos a día de hoy en nuestro derecho positivo. Para ilustrar estas reflexiones conviene recordar algunas de las reacciones doctrinales más sobresalientes formuladas en la última década del siglo XX, tal vez el momento

\footnotetext{
${ }^{33}$ SÁNCHEZ MORÓN, M., "El retorno del derecho administrativo", en Revista de Administración Pública, no 206,2018; GAMERO CASADO, E., "Régimen de los actos separables de los contratos privados del sector público; especial referencia a las entidades instrumentales con personalidad de derecho privado", en Contratación Administrativa Práctica, $\mathrm{n}^{\circ}$ 163, septiembre-octubre, 2019.

${ }^{34}$ DEL SAZ CORDERO, S., "La huida del derecho administrativo: últimas manifestaciones. Aplausos y críticas", en Revista de Administración Pública, n 133, 1994, pág. 57.

${ }^{35}$ CHINCHILLA MARÍN, C., "El derecho de la Unión Europea como freno a la huida del derecho administrativo", en Revista de Administración Pública, nº 200, 2016, pág. 367.

${ }^{36}$ CHINCHILLA MARÍN, C., "El derecho de la Unión Europea como freno a la huida del derecho administrativo", op. cit., pág. 367.
} 
de mayor agudización del problema ${ }^{37} \mathrm{y}$, al propio tiempo de mayor sensibilidad frente al mismo. Estas reacciones doctrinales aunque no de modo exclusivo, quedaron aglutinadas en torno al Congreso homenaje al Profesor M. F. Clavero Arévalo con motivo de su jubilación celebrado en Sevilla en otoño de $1991^{38}$. Quisiera destacar tres posiciones en torno a esta problemática $^{39}$.

A) La que reacciona frente al mencionado fenómeno esgrimiendo una pretendida reserva constitucional de derecho administrativo y de la jurisdicción contencioso-administrativa que dejaría el uso de las fórmulas privatísticas al margen de las soluciones admisibles en el marco de nuestra Constitución ${ }^{40}$. No hay duda de que ésta sería una respuesta contundente de poder articularse efectivamente. Pero, pese a los esfuerzos de su autora, no es fácil hallar en la CE esa genérica reserva. Pues, si bien es cierto que la Constitución impone el sometimiento de la administración al derecho (art. 103. 1) -algo tan obvio que da rubor el recordarlo-, en ninguna parte de su texto puede encontrarse la precisión de que haya de tratarse de una rama concreta del mismo, como es el derecho administrativo. Ni la mención constitucional de la jurisdicción contencioso-administrativa en el art. $153 \mathrm{c}$ ) -excesivamente coyuntural y colateral- puede considerarse como una garantía institucional en su favor, ni la alusión a indudables principios e instituciones específicos del derecho administrativo, e incluso reservas sobre materias específicas a regímenes determinados convencionalmente ubicados en el derecho administrativo, pueden considerarse apoyos suficientes en favor de esa reserva genérica que, de existir, pienso que erradicaría por completo el problema ${ }^{41}$.

La autora de esta tesis tiene sin embargo a favor dos innegables aciertos. De un lado, la propia tesis presupone la necesidad de una ordenación jerárquica de los ordenamientos, el ordenamiento constitucional y la legalidad ordinaria que de existir situaría extramuros de la constitucionalidad las normas legales que contuvieran esas remisiones. Pero, como digo, tal no existe en nuestro derecho pues la Constitución no exige más que el sometimiento al derecho y el derecho privado lo es, no al derecho administrativo. Mas lo que no impone nuestro derecho interno si lo exige el derecho de la Unión Europea, en aquel momento derecho comunitario. A este respecto es de destacar que DEL SAZ cita alguna jurisprudencia comunitaria que ya en

\footnotetext{
37 Una excelente exposición del desarrollo del desarrollo del sometimiento al derecho privado y correlativa contracción de la aplicación del derecho administrativo en el funcionamiento de las administraciones públicas puede encontrarse en DEL SAZ CORDERO, S., "La huida del derecho administrativo: últimas manifestaciones. Aplausos y críticas", op. cit..

${ }^{38}$ Especial interés revisten MARTIN RETORTILLO, S. "Las empresas públicas: reflexiones del momento presente", publicado después en Revista de Administración Pública, número 126, 1991; y VILLAR PALASI, J.L., "Tipología y Derecho estatutario de las Entidades instrumentales de las Administraciones públicas", Administración Instrumental. Libro Homenaje a Manuel Francisco Clavero Arévalo, Civitas, 1994.
}

${ }^{39}$ Para una exposición mucho más detalladas del enfrentamiento doctrinal en este punto puede verse DEL SAZ CORDERO, S., "La huida del derecho administrativo: últimas manifestaciones. Aplausos y críticas", op. cit. .

${ }^{40}$ DEL SAZ CORDERO, S. "Desarrollo y crisis del Derecho administrativo. Su reserva constitucional". En Nuevas perspectivas del Derecho administrativo. Tres estudios, Civitas, 1992, pág. 174.

${ }^{41}$ DEL SAZ CORDERO, S., "Desarrollo y crisis del Derecho administrativo. Su reserva constitucional”, op. cit., págs. $179 \mathrm{y}$ ss. 
1993 condenaba al Reino de España por no utilizar en determinados supuestos procedimientos públicos de selección de contratistas ${ }^{42}$.

Además, deseo destacar en este momento que esta autora apunta una solución ${ }^{43}$ que, andando el tiempo, ha sido acogida por nuestro derecho positivo en la vigente ley 9/2017, de 8 de noviembre, de Contratos del Sector Público, por la que se transponen al ordenamiento jurídico español las Directivas del Parlamento Europeo y del Consejo 2014/23/UE y 2014/24/UE, de 26 de febrero de 2014 (LCSP) en su art. 41.2.a) que me referiré más adelante, sin duda bajo la presión del derecho de la Unión

B) Otra posición doctrinal en su momento tomaba como punto de partida el que la aplicación del derecho privado, a fin de cuentas también derecho, no representa una ocasión para la consagración de inmunidades $y$, en consecuencia no tendría que suponer necesariamente una huida del derecho y dadas las ventajas que se podrían conseguir con esta aplicación, sería beneficiosa pues, según los autores que sostienen esta tesis, existen mecanismos suficientes en el propio derecho privado y en el sometimiento a la jurisdicción ordinaria para evitar el riesgo de huida del derecho y refugio en la inmunidad, que es, en definitiva, lo que se trata de evitar ${ }^{44}$.

En efecto, tras apurar las posibilidades de las modulaciones que el derecho privado experimenta ante la presencia de las administraciones públicas por exigencia del Código civil, el derecho comunitario y la Constitución, se concluía en que realmente la huida del derecho administrativo no es nada más que la huida de "las grandes leyes administrativas. Al abandonarlas el legislador confia el derecho administrativo a su fuente originaria: la jurisprudencia de los Tribunales. Este fenómeno nos obliga a recordar que el Droit administratif es una obra pretoriana; y que nuestra propia experiencia histórica enseña que la jurisprudencia del Consejo Real, y los Reales Decretos de conflictos tuvieron un protagonismo indudable en la creación de las instituciones e institutos propios del Derecho administrativo, luego plasmados en la obra legisladora que se condensó en determinados momentos, como la Revolución Gloriosa, la Restauración, la década de 1920, o los años 50.

La huida de las leyes administrativas lleva a que deba ser la jurisprudencia la que, en el intersticio de los textos legales de las leyes civiles mercantiles y laborales, cree un Derecho adecuado para las Administraciones públicas ${ }^{45}$ ".

Con independencia de que no puede afirmarse que la jurisprudencia haya jugado entre nosotros un papel de la amplitud que de las palabras citadas se desprende -otra cosa es lo que ocurriera en Francia y el protagonismo del Conseil d' Etat, incluso algunas actuaciones concretas de la

\footnotetext{
42 DEL SAZ CORDERO, S. "La huida del derecho administrativo: últimas manifestaciones. Aplausos y críticas", op. cit., págs. 88 y ss.

${ }^{43}$ DEL SAZ CORDERO, S., "La huida del derecho administrativo: últimas manifestaciones. Aplausos y críticas", op. cit., pág. 92.

44 BORRAJO INIESTA, I., "El intento de huir del Derecho administrativo", en Revista Española de Derecho Administrativo, $\mathrm{n}^{\circ} 78,1993$.

${ }^{45}$ BORRAJO INIESTA, I., "El intento de huir del Derecho administrativo”, op. cit., pág. 242.
} 
jurisprudencia española- y de que, pese a lo que digan, la historia no se repite, no deja de ser valiosa la metodología que se sugiere: se trata de abordar la renovación del derecho administrativo a partir de un derecho privado que acerca sus modos de actuar a principios tradicionales del derecho público ${ }^{46}$. La realidad demuestra que este planteamiento no ha sido suficiente porque la raíz del mal siempre ha estado en las preferencias del legislativo. También en estas tesis merece destacarse la referencia al derecho comunitario que entonces de una forma incipiente y en la actualidad de manera decisiva va a constituir la solución al problema que planteamos, al menos, en este momento.

C) Una tercera posición intentó en el pasado acometer la reacción frente al problema que nos ocupa mediante una reordenación de los tipos de entes públicos de carácter instrumental, en torno al concepto de organismo autónomo. Junto con la redefinición de estos tipos, eliminando algunas figuras organizativas de perfiles confusos y de difícil justificación -las sociedades estatales-, es necesario predeterminar los criterios que permitan el sometimiento de la actividad administrativa al derecho privado, excluyendo la que supongan ejercicio de poderes soberanos. En relación con éstos, nunca habrá razones suficientes que justifiquen el uso del derecho privado.

Al margen de los supuestos que se determinasen claramente, el uso del derecho privado y las formas societarias sólo tendrían sentido en el ámbito de servicios o actividades que se presten en régimen de concurrencia. Ahí la experiencia -especialmente inglesa- ha demostrado que la vieja idea de la publicatio o reserva al Estado de todo servicio o sector ha quedado superada a medida en que se van superando los llamados monopolios naturales ${ }^{47}$.

También se quiso ver en el art. 2.2 de la ya derogada Ley 30/1992, de 26 de noviembre, de Régimen Jurídico de las Administraciones Públicas y de Procedimiento Administrativo Común $^{48}$, una reacción frente al fenómeno que trato ${ }^{49}$. La caracterización como administraciones públicas de estos entes; su sujeción al derecho administrativo para el ejercicio de sus potestades públicas y las limitaciones que parecen desprenderse para el empleo del derecho privado en el ámbito no reservado al derecho administrativo, se ha dicho, son reglas acreedoras de especial relevancia. La doctrina en si es acertada, pero no podía superar el defecto de fondo del sistema: todo dependía de un legislador no siempre dispuesto a colaborar.

\footnotetext{
${ }^{46}$ En este sentido me parecen muy sugerentes las consideraciones que realiza VILLAR PALASI, J. L. en "Tipología y Derecho estatutario de los entes instrumentales de las Administraciones públicas", Libro homenaje al Profesor M. F Clavero Arévalo, Civitas, 1994.

${ }^{47}$ SALA ARQUER, J.M., "Huida al Derecho privado y huida del Derecho", en Revista Española de Derecho Administrativo, $\mathrm{n}^{\circ} 75,1992$.

48 "Las Entidades de Derecho público con personalidad jurídica propia vinculadas o dependientes de cualquiera de las Administraciones públicas tendrán asimismo la consideración de Administración pública. Estas Entidades sujetarán su actividad a la presente Ley cuando ejerzan potestades administrativas, sometiéndose en el resto de su actividad a lo que dispongan sus normas de creación".

${ }^{49}$ GARCÍA DE ENTERRÍA, E./ FERNÁNDEZ RODRÍGUEZ, T.R., Curso de Derecho administrativo, I, Civitas, 1993, pág. 391; LÓPEZ RAMÓN, F., "Reflexiones sobre el ámbito de aplicación de la Ley de Régimen Jurídico de las Administraciones Públicas”, en Revista de Administración Pública, nº 130 1993, págs 113 y ss.
} 
En este contexto nos encontrábamos ante un problema insoluble desde una perspectiva jurídica o, por mejor decir, ante un problema que propiamente no debe plantearse en términos jurídicos si se desea llegar a una solución ${ }^{50}$. O bien que para llegar a una solución aceptable era necesario arbitrar un mecanismo que sometiese al legislador a aceptar tan atinadas razones como se encuentran en todos los planteamientos doctrinales consignados. Ese orden jurídico ha sido precisamente e derecho de la Unión.

\subsection{La posible solución de la mano del derecho de la Unión Europea}

Recientemente varios autores ${ }^{51}$ han subrayado el crucial papel que el derecho de la Unión Europea ha jugado en encauzar, si no superar por completo, el problema que nos ocupa. De estos estudios se desprende que el derecho de la Unión está cercenando las posibilidades de huida del derecho administrativo en dos frentes importantes. Por un lado, el de la creación de entes con sustrato público y que rigen su actuación por el derecho privado y, por otro, la imposición de procedimientos públicos de contratación más allá del ámbito de las administraciones públicas para abarcar el mucho más amplio de los entes integrados en el sector público.

Por lo que respecta a la legislación de contratos, desde principios de la última década del siglo pasado la UE a impulsos primero de la jurisprudencia, después a través de diversas directivas ha forzado una corrección de las normas internas que ha obligado a extender el marco de la contratación pública de las administraciones públicas -ley de contratos de las administraciones públicas- a otros sujetos. Primero entes públicos con independencia de su forma mediante la acuñación del concepto de poder adjudicador, incluido en nuestro derecho en la Ley 30/2007, de 30 de octubre, de contratos del sector público, hasta la previsión del artículo 41. 2 de la Ley 9/2017, de 8 de noviembre,de que tendrán la consideración de actos administrativos los actos preparatorios y los actos de adjudicación de los contratos de las entidades del sector público que no sean Administraciones Públicas, así como los actos preparatorios y los actos de adjudicación de los contratos subvencionados a que se refiere el artículo 23 de la presente Ley, dicho de forma más expresa, se pueden considerar actos administrativos actos procedentes de sujetos privados, medida que si no revolucionaria ${ }^{52}$, como se dicho, si es trascendental a efectos

${ }^{50}$ En definitiva, esta parece ser la conclusión a que llegan GARCÍA DE ENTERRÍA, E. y FERNÁNDEZ RODRÍGUEZ, T.R., Curso de Derecho administrativo I, op. cit., pág. 390.

${ }^{51}$ CHINCHILLA MARÍN, C., "El derecho de la Unión Europea como freno a la huida del derecho administrativo", en Revista de Administración Pública, no 200, 2016;SÁNCHEZ MORÓN, M., "El retorno del derecho administrativo", en Revista de Administración Pública, $n^{\circ}$ 206,2018; y GAMERO CASADO, E., "Régimen de los actos separables de los contratos privados del sector público; especial referencia a las entidades instrumentales con personalidad de derecho privado", en Contratación Administrativa Práctica nº 163, septiembre-octubre, 2019.

52 SÁNCHEZ MORÓN, M., "El retorno del derecho administrativo.”, en Revista de Administración Pública, $\mathrm{n}^{\circ}$ 206, pág 64 (en nota 35) ha recordado que "en Francia, por ejemplo, el Conseil d'État reconoce la naturaleza de actos administrativos a las decisiones adoptadas por organismos de derecho privado en el cumplimiento de misiones de servicio público que implican el ejercicio de prerrogativas públicas desde el ârret Monpeurt, de 31 de julio de 1942, y el ârret Magnier, de 13 de enero de 1961". 
de rectificar la deriva que consideramos pudiendo hablarse del retorno del derecho administrativo $^{53}$.

También se ha señalado como las normas de la Unión Europea con ocasión de la reforma del sistema europeo de cuentas nacionales y regionales, que se concreta en el denominado SEC2010,aprobada por el Reglamento (UE) 549/2013, del Parlamento Europeo y del Consejo, de 21 de mayo de 2013 han impuesto un importante bloqueo a la posibilidad, hasta ahora prácticamente incondicionada, de crear incluso por ley entes públicos regidos por el derecho privado y, en consecuencia, impone la necesidad de la aplicación del derecho administrativo si no se financian mayoritariamente con ingresos de mercado. Así se ha recogido en el artículo 103.1 LRJSP referido a las entidades públicas empresariales. Esta previsión recorta también las posibilidades de las sociedades mercantiles estatales (art. 113 LRJSP) queen ningún caso podrán disponer de facultades que impliquen el ejercicio de autoridad pública. No obstante, son criticables y de difícil compatibilidad con el derecho de la Unión la posibilidad contemplada en el art. 103. 3 de que las entidades públicas empresariales puedan ejercer potestades administrativas aunque se limite su ejercicio a aquellos órganos de éstas a los que los estatutos les asigne expresamente esta facultad (art.105. 1) o en el art 113, aunque sea excepcionalmente, como allí se indica, respecto de las sociedades mercantiles estatales.

Ninguno de estos preceptos tiene la consideración de norma básica, pero el contenido traspuesto del derecho de la Unión alcanza yvincula también a las legislaciones autonómicas a la hora de regular estas materias. De esta manera queda claro el ámbito en que los entes del sector público pueden acudir al derecho privado.

\section{CONCLUSIÓN}

Cualquier lector informado puede advertir enseguida que en este trabajo no hay aportación alguna novedosa. Es más, me atrevo a afirmar que no obtendría una evaluación positiva de la CAYCIT u organismo similar si aquélla no existe ya, para otorgar sexenios de investigación. Soy perfectamente consciente. Pero este trabajo, el último antes de mi jubilación y posiblemente el último sin más y terminado en pleno confinamiento provocado por la pandemia del COVT 19 , no tiene esa finalidad.

Estas páginas no tienen otra finalidad que subrayar la trascendencia de uno de los dos acontecimientos más relevantes para el derecho administrativo en estos casi cincuenta años en que he convivido con él: la Constitución de 1978 y nuestra incorporación a la Unión Europea, entonces Comunidad Económica Europea, en 1986. Y lo hago, realzando especialmente este último, precisamente cuando los populismos de uno y otro signo, lo cuestionan y muy especialmente cuando, en ocasiones, el comportamiento de los socios europeos puede parecer, o incluso ser, decepcionante.

\footnotetext{
${ }^{53}$ GAMERO CASADO, E., "Régimen de los actos separables de los contratos privados del sector público; especial referencia a las entidades instrumentales con personalidad de derecho privado", op. cit. pág. 10.
} 
Acaso se me puede tildar de exagerado, pero estoy convencido de que la Unión Europea es el acontecimiento más positivo que ha sobrevenido a Europa desde el advenimiento del cristianismo. Lo afirmo consciente de sus actuales limitaciones y deficiencias, por lo que creo que todos los europeos en la medida de nuestras fuerzas tenemos el deber de apoyar una estructura jurídico política que ha posibilitado al menos setenta y cinco años sin guerras en la gran parte de Europa en que nos ha tocado vivir, además, en un entorno de libertad y democracia envidiable en la mayor parte del mundo. A partir de ahí estoy dispuesto a reconocer todo tipo de insuficiencias y deficiencias que no hacen sino indicar el largo camino que aún queda por recorrer.

\section{BIBLIOGRAFÍA}

AHUMADA RUIZ, M.A., "Responsabilidad patrimonial del Estado por las leyes inconstitucionales (o el derecho a no ser perjudicado por una ley inconstitucional)", en Revista Española de Derecho Constitucional, n 42, 2001.

ALONSO GARCÍA, R., "La responsabilidad patrimonial del Estado-legislador, en especial en los casos de infracción del Derecho comunitario: a propósito del auto del Tribunal Supremo de 1 de febrero de 2008 y la cuestión prejudicial planteada al TJCE (C118/08)", en Cuadernos de Derecho Local, núm.19, 2009.

BORRAJO INIESTA, I., "El intento de huir del Derecho administrativo", en Revista Española de Derecho Administrativo, no 78, 1993.

CHINCHILLA MARÍN, C., "El derecho de la Unión Europea como freno a la huida del derecho administrativo", en Revista de Administración Pública, no 200, 2016.

COBREROS MENDAZONA, E., "El diálogo judicial para la construcción de la responsabilidad patrimonial del estado por leyes contrarias al derecho de la unión europea", Anuario de la Facultad de Derecho de la Universidad Autónoma de Madrid, $\mathrm{n}^{\mathrm{o}} 22,2018$.

COBREROS MENDAZONA, E., "La pertenencia a la Unión Europea y su repercusión en la responsabilidad patrimonial”, en Revista de Administración Pública, nº 200, 2016.

COBREROS MENDAZONA, E., Responsabilidad patrimonial del Estado por incumplimiento del Derecho de la Unión Europea, Iustel, 2015.

COBREROS MENDAZONA, E., "La exigibilidad del requisito de la violación suficientemente caracterizada al aplicar en nuestro ordenamiento el principio de la responsabilidad patrimonial de los estados por el incumplimiento del derecho de la Unión Europea”, en Revista de Administración Pública, nº 196, 2015.

CORTÉS MARTÍN, J.M., “Jurisprudencia del Tribunal de Justicia de la Unión Europea”, en Revista de Derecho comunitario Europeo, enero-abril, 2010. 
DEL SAZ CORDERO, S., "La huida del derecho administrativo: últimas manifestaciones. Aplausos y críticas", en Revista de Administración Pública, nº 133, 1994.

DEL SAZ CORDERO, S., "Desarrollo y crisis del Derecho administrativo. Su reserva constitucional", en Nuevas perspectivas del Derecho administrativo. Tres estudios, Civitas, 1992.

GALÁN VIOQUE, R., “A vueltas con la regulación de la responsabilidad del Estado legislador (Un nuevo intento introducido en el Proyecto de Ley de Régimen jurídico del sector público de limitar el alcance de la responsabilidad del Estado Legislador, esta vez en su vertiente del ilícito legislativo)", en Documentación Administrativa, nueva época, $\mathrm{n}^{\circ} 2$, 2015 .

GAMERO CASADO, E., "Régimen de los actos separables de los contratos privados del sector público; especial referencia a las entidades instrumentales con personalidad de derecho privado", en Contratación Administrativa Práctica, nº 163, 2019.

GARCÍA DE ENTERRÍA, E., La responsabilidad patrimonial del Estado legislador en el Derecho español, Civitas, 2005.

GARCÍA DE ENTERRÍA, E. /FERNÁNDEZ RODRÍGUEZ, T.R., Curso de Derecho administrativo, I, Civitas, 1993.

GUICHOT REINA, E., "La responsabilidad del Estado legislador por infracción del Derecho de la Unión Europea en la jurisprudencia y en la legislación español a la luz de los principios de equivalencia y efectividad", en Revista Española de Derecho Europeo, $\mathrm{n}^{\circ}$ 60, 2016.

LÓPEZ RAMÓN, F., "Reflexiones sobre el ámbito de aplicación de la Ley de Régimen Jurídico de las Administraciones Públicas", en Revista de Administración Pública, nº 130, 1993.

MANGAS MARTÍN, A., “Cuestiones Jurídicas en torno al Brexit: notificación, plazos, formación de la voluntad, orientaciones y revocación”, en Anuario Español de Derecho Internacional, $\mathrm{n}^{\mathrm{o}}$ 34, 2018.

MARTÍN RETORTILLO, S., "Las empresas públicas: reflexiones del momento presente”, en Revista de Administración Pública, nº 126, 1991.

MORENO MOLINA, J.A., "Las novedades en la regulación por las leyes 39 y 40/2015 de la responsabilidad patrimonial y la potestad sancionadora de las administraciones públicas”, en Revista Española de Derecho Administrativo, n 179, 2016.

NIETO, A., "El Derecho comunitario europeo como Derecho común vulgar", en Revista de Administración Pública, no 200, mayo- agosto, 2016.

SALA ARQUER, J.M., "Huida al Derecho privado y huida del Derecho", enRevista Española de Derecho Administrativo, no 75, 1992. 
SÁNCHEZ MORÓN, M.,"El retorno del derecho administrativo", en Revista de Administración Pública, $\mathrm{n}^{\circ} 206$.

SARMIENTO, D., El Derecho de la Unión Europea (2ª edición), Marcial Pons, 2018.

VILLAR PALASÍ, J.L., “Tipología y Derecho estatutario de las Entidades instrumentales de las Administraciones públicas", en Administración Instrumental. Libro Homenaje a Manuel Francisco Clavero Arévalo. Civitas, 1994. 